\title{
Diuretic effect of chlorogenic acid from traditional medicinal plant Merremia emarginata (Burm. F.) and its by product hippuric acid
}

Rameshkumar Angappan ${ }^{1}$, Arul Ananth Devanesan ${ }^{1,2}$ and Sivasudha Thilagar ${ }^{1 *}$

\begin{abstract}
Background: Medicinal and aromatic plants exhibit important pharmacological activities to human. The present study evaluates the diuretic activity of aqueous extract of Merremia emarginata (MEAE).

Methods: Female Wistar albino rats were used for diuretic activity in vivo studies. Urinary hippuric acid of treated animal group was successfully quantified by RP-HPLC. UPLC-MS/MS is used for the identification of important bioactive compound in MEAE.

Results: Diuretic activity was confirmed through analyzing the disparity in total volume and diuretic markers (total sodium and potassium concentration of urine) which was compared to normal group rats. MEAE plays a crucial role for inducing diuretics without side effects such as glycosuria or proteinuria. This activity was significantly high $(p<0.05)$ compared to control group rats and diuretic responsible polyphenolic compound chlorogenic acid was identified in MEAE through RP-HPLC and UPLC-MS/MS.

Conclusion: Hippuric acid is a byproduct of chlorogenic acid and reported to be responsible for inducing diuretics. Secondary metabolites such as chlorogenic acid and their byproducts might be responsible for diuretic activity. Hippuric acid can act as a diuretic agent as well as it could be used as a biomarker to detect the polyphenolics induced diuretic activity. M. emarginata can act as an excellent diuretic agent, without causing any harmful side effects.
\end{abstract}

Keywords: M. emarginata, RP-HPLC, UPLC-MS/MS, Diuretic activity, Chlorogenic acid, Hippuric acid

\section{Background}

Merremia emarginata (Burm. f.) belongs to family Convolvulaceae is prevalent throughout India and tropical region of Asia. This plant is uncultivated food crop used by people in India as green leaf vegetable and creeping perennial herb rooting at the nodes. M. emarginata traditionally used as diuretic, deobstruent, rheumatism, neuralgia, cough and headache [1]. Previous reports suggested that M. emarginata leaves have strong antioxidant property and antibacterial activity against both gram positive and gram negative bacterial $[2,3]$.

\footnotetext{
* Correspondence: sudha@bdu.ac.in; sudacoli@yahoo.com

${ }^{1}$ Department of Environmental Biotechnology, Bharathidasan University,

Tiruchirappalli, Tamil Nadu 620024, India

Full list of author information is available at the end of the article
}

A diuretic drug is any substance that elevates the urine excretion, they are widely used for treatment of edema, congestive heart failure, hypertension, liver and kidney diseases [4]. Now a day's many commercial diuretic drugs available in the market are class of thiazide (chlorothiazide, hydrochlorothiazide etc), loop (furosemide, bumetanide etc), $\mathrm{K}^{+}$sparing (amioloride, eplerenone etc) and CA inhibitors (acetazolamide, dichlorphenamideetc). These commercial diuretics drugs have variety of side effects such as hypokalemia, metabolic alkalosis, dehydration (hypovolemia), leading to hypotension, fever, cough, unusual bleeding, excessive weight loss, nausea, vomiting [5]. Diuretic drugs of medicinal plants origin are a better alternative to commercial diuretic drugs. Wright et al. [6] reported that about hundreds of medicinal plants 
and its extracts were successfully investigated for their diuretic property. The most successful and most potential diuretic medicinal plant genus includes Spergularia purpurea, Petroselinum sativum, Foeniculum vulgare and $\mathrm{Hi}$ biscus sabdariffa [7-10]. These medicinal plants contain secondary metabolites (alkaloids, phenolics and flavonoids etc.) which might be responsible for diuretic activity [11, 12]. But there is no previous report about specific phenolic compound and its byproduct for diuretic activity. The mechanism of medicinal plant induces diuretic activity is still unclear. Further, Kaur, [13] reported that, cow urine containing hippuric acid responsible for induced diuretic activity. Based on this, the present study was carried out to study the diuretic activity of MEAE. Chlorogenic acid which is one of the phenolic compounds found in MEAE and hippuric acid is a byproduct of chlorogenic acid was detected in our plant extract treated rat urine sample through RP-HPLC which indirectly reveals about the role of polyphenolics present in the plant extract in inducing diuretics.

\section{Methods \\ Plant collection}

Fresh leaves of $M$. emarginata were collected from Dharmapuri, Tamil Nadu in India. The identity of the plant was authenticated by the Department of Plant Science, Bharathidasan University, Tiruchirappalli. The leaves were picked and washed with distilled water to remove all the unwanted debris and shade dried under room temperature of $30{ }^{\circ} \mathrm{C}$ for 10 days, ground into powder using electronic grinder and stored in an airtight container until further use.

\section{Preparation aqueous extract}

Ten gram of powdered plant material was extracted with distilled water $\left(250 \mathrm{ml} ; 27-30{ }^{\circ} \mathrm{C}\right)$ on shaker (Orbitec-scigenics Biotech, India) for $48 \mathrm{~h}$. The extract was filtered and quickly frozen at $-80{ }^{\circ} \mathrm{C}$ and dried for $48 \mathrm{~h}$ using a vacuum freeze dryer (Christ alpha 1-2 / LD plus, Germany) to give a yield of $8.87 \%$ of dry extract. The resulting extract was reconstituted with distilled water to give desired concentrations and used for further analysis.

\section{In vivo studies}

Adult female Wistar albino rats weighing 150-200 g were housed in standard cages with good feed and water access. Experimental procedures and protocols were approved by the committee (BDU/IAEC/2012/33/28/03/2012) for the purpose of CPCSEA, Chennai, Tamil Nadu, India.

\section{Experimental method}

Diuretic activity was carried out by Biswas et al. [14] method. Animals were divided into five groups each with five rats. Before starting the experiment, the rats were starved for $18 \mathrm{~h}$. Among the five groups, group one served as a control which was fed normal drinking water only (10 ml/kg b.w.). Second group served as a commercial diuretic drug treated (furosemide $20 \mathrm{mg} / \mathrm{kg}$ b.w.). The third, fourth and fifth groups received MEAE orally at the doses of 200, 400 and $600 \mathrm{mg} / \mathrm{kg}$ b.w. respectively. After administration of drugs (orally), animals were caged immediately under sterile condition. Urine samples were collected up to $5 \mathrm{~h}$, during the experiment, food and water was not given to the animals in cages. After collection, urine samples were preserved with sodium azide to avoid microbial contamination. Further, urine $\mathrm{Na}^{+}$and $\mathrm{K}^{+}$ions were analyzed by flame photometer (Elico. CL 378, India) [15]. Total protein was estimated by Bradford standard protocol [16] and glucose was analyzed through Ortho tolludine method [17].

\section{Identification and quantification of hippuric acid through RP-HPLC}

Rat urine was centrifuged at $13000 \mathrm{rpm}$ for $4 \mathrm{~min}$ at $4{ }^{\circ} \mathrm{C}$. The resulting supernatant was used for further analysis. The RP-HPLC on a $\mathrm{C}_{18}$ column $(4.6 \times 250 \mathrm{~mm}, 5 \mu \mathrm{m}$ particle size) was used for hippuric acid identification. Analytical HPLC system employed consists of Waters high performance liquid chromatography coupled with a photodiode array detector (PDA-2998), USA. Mobile phase consist of water with $0.1 \%$ formic acid (Solvent A) and $100 \%$ methanol (Solvent B), the gradient program followed; Solvent A and B was $0-10 \%$ (5 min), $10-15 \%$ (5 min), $15-20 \%$ (5 min), $20-30 \%$ (5 min), $30-40 \%$ (10 min); Flow rate was $1 \mathrm{ml} / \mathrm{min}$. Detection was carried out in the multi wavelength detection range of 210 to 400 [18]. Hippuric acid presence in urine sample was confirmed by comparing its retention time and $\lambda$ max of an authentic standard.

\section{Chlorogenic acid identification by UPLC-MS/MS}

UPLC was carried out using Waters UPLC system with PDA detector by Waters Corporation, USA. $\mathrm{C}_{18}$ UPLC column (150 mm X $2.1 \mathrm{~mm}$ dia X $1.7 \mu \mathrm{m}$ particle size) used for chlorogenic acid identification. The mobile phase was similar as followed in RP-HPLC analysis. Gradient program was optimized according to UPLC condition. Mass Spectrometric analysis of phenolic compounds carried out by SYNAPT Mass Spectrometer from Waters, USA with ESI mode. Compounds were analyzed both positive and negative modes.

\section{Statistical analysis}

All the statistical data were analyzed through SPSS 16.0 and Origin 6.0. The significance of difference between the groups was determined using one way ANOVA. All data were expressed as mean \pm standard deviation (SD). The significance level was expresses as $p<0.05$. 
Table 1 Effect of MEAE on diuretic excretion parameters of albino Wistar rat urine

\begin{tabular}{|c|c|c|c|c|c|}
\hline Treatment Groups & $\begin{array}{l}\text { Total volume of Urine } \\
(\mathrm{ml} / 5 \mathrm{~h})\end{array}$ & $\begin{array}{l}\text { Total Sodium } \\
(\mathrm{mEq} / \mathrm{l})\end{array}$ & $\begin{array}{l}\text { Total Potassium } \\
(\mathrm{mEq} / \mathrm{l})\end{array}$ & $\begin{array}{l}\text { Total Protein } \\
(\mu \mathrm{mol} / \mathrm{dl})\end{array}$ & $\begin{array}{l}\text { Total Glucose } \\
(\mathrm{mg} / \mathrm{dl})\end{array}$ \\
\hline Control & $1.55 \pm 0.03^{d}$ & $120.3 \pm 1.2^{\mathrm{e}}$ & $210.6 \pm 1.1^{\mathrm{e}}$ & $1.162 \pm 0.1^{c}$ & $2.3 \pm 0.5^{d}$ \\
\hline Furosemide (20 mg/kg b.w.) & $3.58 \pm 0.08^{\mathrm{a}}$ & $225.7 \pm 1.9^{d}$ & $365.1 \pm 1.8^{\mathrm{a}}$ & $1.249 \pm 0.02^{\mathrm{a}}$ & $6.3 \pm 0.07^{\mathrm{a}}$ \\
\hline MEAE (200 mg/kg b.w.) & $1.46 \pm 0.02^{e}$ & $309.1 \pm 2.2^{c}$ & $243.1 \pm 1.5^{\mathrm{d}}$ & $0.667 \pm 0.01^{e}$ & $3.4 \pm 0.12^{c, b}$ \\
\hline MEAE (400 mg/kg b.w.) & $1.83 \pm 0.04^{c}$ & $325.3 \pm 1.8^{\mathrm{b}}$ & $289.4 \pm 2.1^{c}$ & $0.817 \pm 0.01^{d}$ & $3.5 \pm 0.07^{c, a}$ \\
\hline MEAE (600 mg/kg b.w.) & $2.61 \pm 0.05^{b}$ & $345.1 \pm 1.3^{\mathrm{a}}$ & $349.4 \pm 1.7^{b}$ & $1.218 \pm 0.01^{b}$ & $4.1 \pm 0.04^{b}$ \\
\hline
\end{tabular}

Mean \pm SD obtained from analysis of three independent samples, in duplicate

abcde; In each column, the superscript letters significantly differences in the mean at $(P<0.05)$ level

\section{A}

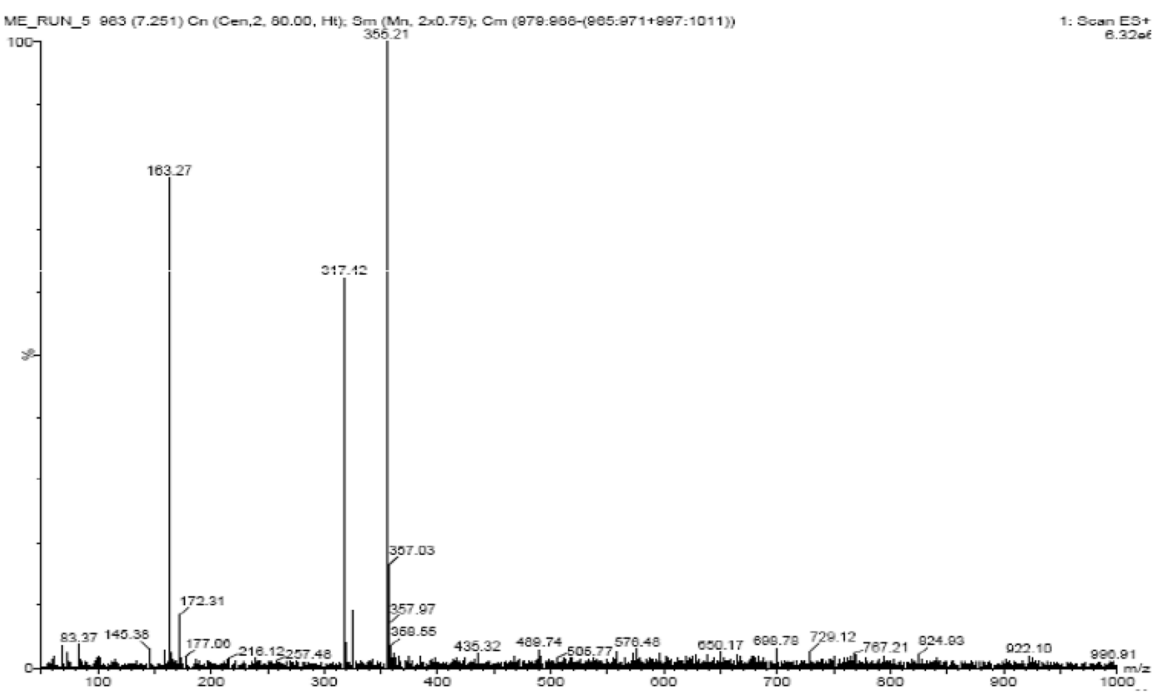

B

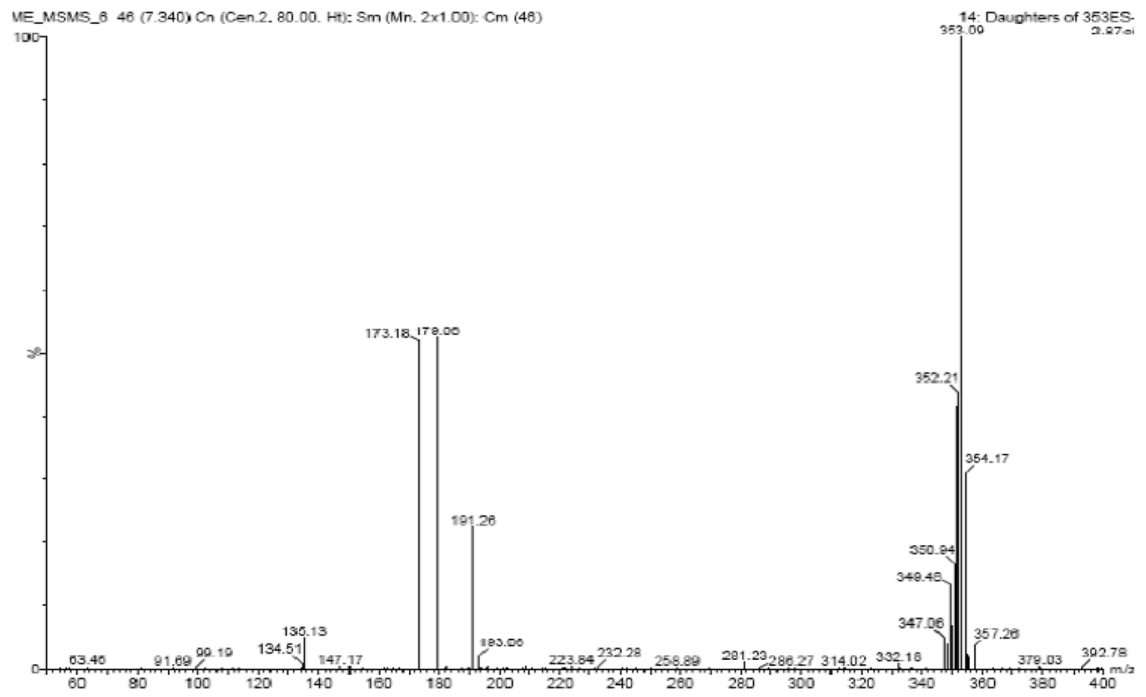

Fig. 1 UPLC-MS/MS analysis shows chlorogenic acid fragmentation pattern in both positive and negative ion mode $\left(\mathbf{1} \mathbf{a}\right.$. Positive $[\mathrm{M}-\mathrm{H}]^{+}, \mathbf{1 b}$ Negative $[\mathrm{M}-\mathrm{H}]^{-}$ion mode) 


\section{Results and discussion}

\section{Diuretic and excretion parameters analysis}

The volume of urine measured up to $5 \mathrm{~h}$. Table 1 shows total volume of urine excretion, total sodium, total potassium, total protein and total glucose concentration in the rat urine samples. Total volume of urine excretion data shows (MEAE) and furosemide (Lasix) treated rat group excreted high volume of urine compared to untreated control group. MEAE treated rat groups urine excretion had increased in a dose dependant manner. Furosemide (20 mg/kg b.w) treated animal group urine volume $(3.55 \pm 0.03 \mathrm{ml} / 5 \mathrm{~h})$ is very high when compared

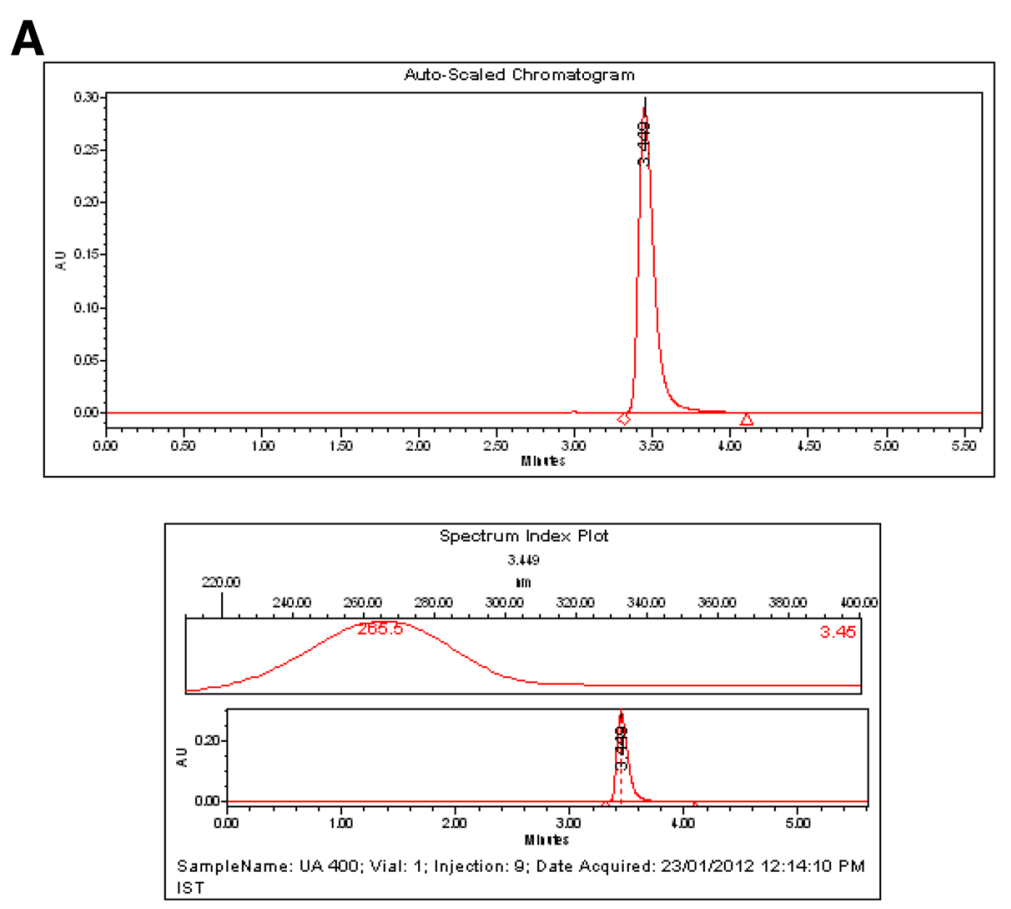

B
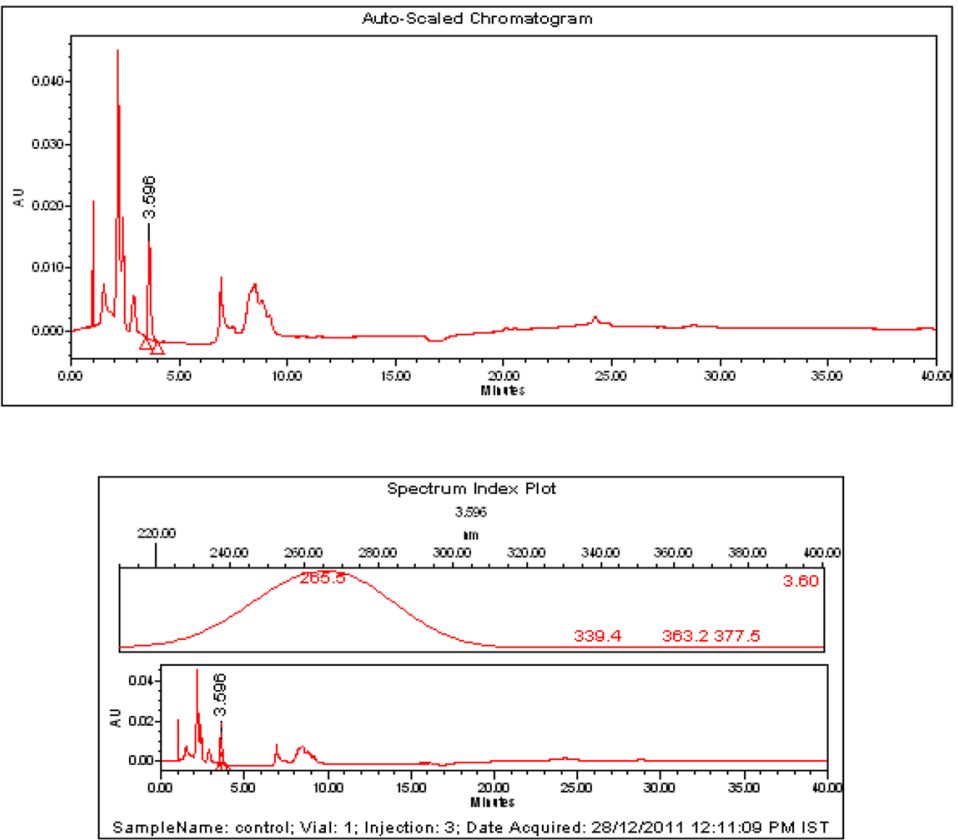

Fig. 2 a RP-HPLC chromatograms (photo-diode array detector set at 200-400 nm). Hippuric acid (HA) standard maximum absorption ( $\lambda$ max) is at $265.5 \mathrm{~nm}$ and Retention time is $3.4 \mathrm{~min}$. b RP-HPLC chromatograms (PDA detector set at 200-500 nm). Hippuric acid (HA) analysis from MEAE treated albino Wistar rat urine sample. Maximum absorption $(\lambda$ max) is at $265.5 \mathrm{~nm}$ and Retention time is at $3.5 \mathrm{~min}$ 
to $600 \mathrm{mg} / \mathrm{kg}$ b.w MEAE treated group, $(2.61 \pm 0.05 \mathrm{ml} /$ $5 \mathrm{~h}$ ), volume of urine at when the total sodium and potassium levels were significantly increased $(p<0.05)$ in the treated animal group when compared to control group. Total protein and glucose levels in urine samples of MEAE treated animal groups were similar to control group. These results clearly indicate that the plant doesn't produce side effects such as either proteinuria or glycosuria.

\section{Identification of chlorogenic acid through RP-HPLC and UPLC-MS/MS}

Occurrence of chlorogenic acid in the MEAE was confirmed by comparing with chlorogenic acid standard (HPLC grade, Sigma) retention time, absorbance spectrum and mass analysis through MS/MS fragmentation (Fig. 1a and b). The presence of chlorogenic acid in MEAE was detected through UPLC-MS/MS and confirmed by MS/MS fragmentation pattern in both positive $[\mathrm{M}-\mathrm{H}]^{+}$and negative $[\mathrm{M}-\mathrm{H}]^{-}$mode ionization. The chlorogenic acid exact molar mass is 354.09. Fig. 1a shows chlorogenic acid in $[\mathrm{M}-\mathrm{H}]^{+}$mode, the mass of base peak gave $[\mathrm{M}-\mathrm{H}]^{+}$ion at $\mathrm{m} / z$ is 355.21 , and $\mathrm{MS}^{2}$ fragmentation $[\mathrm{M}-\mathrm{H}]^{+}$ion shows at 163.07. In negative $[\mathrm{M}-\mathrm{H}]^{-}$ion mode (Fig. 1b), chlorogenic acid shows a base peak at 353.09 , and $\mathrm{MS}^{2}$ fragmentation $[\mathrm{M}-\mathrm{H}]^{-}$ion shows at $191.26,173.18$ and 135.13 respectively. It was same fragmentation pattern previously reported $[19,20]$.

\section{Detection and quantification of hippuric acid through RP- HPLC analysis}

Gonthier et al. [21] studied about chlorogenic acid degradation through gut microbial pathway. Their result shows the chlorogenic acid degradation or digestion through gut microorganisms, from this microbial degradation, chlorogenic acid produced byproducts namely hippuric acid and 3- hydroxyhippuric acid. This hippuric acid can act as diuretic agent [13], but the mechanism of hippuric acid acting as diuretics is still unclear.

The filtered urine sample was injected into RP-HPLC to determine the hippuric acid content. The presence of hippuric acid in the urine was confirmed by comparing the peak with retention time and absorbance spectrum of commercial hippuric acid standard. The absorbance maximum at $265.5 \mathrm{~nm}$ and retention time of $3.449 \pm 0.1 \mathrm{~min}$ was observed in both commercial hippuric acid standard and urine sample (Fig. 2a and b). Hippuric acid content of the urine samples (control and drug treated) were determined based on the hippuric acid standard curve $(y=$ 5342.x $-35,193, R^{2}=0.999$ ). Hippuric acid content of control and furosemide treated was 97.25 and $566.3 \mathrm{ng} / \mathrm{ml}$ respectively. MEAE treated (200, 400 and $600 \mathrm{mg} / \mathrm{kg}$ b.w) groups showed hippuric acid content 240.8, 494.9 and
$620.7 \mathrm{ng} / \mathrm{ml}$ respectively (Table 2 ). Control and furosemide treated excretion of hippuric acid perhaps due to benzoic acid conjugated hippuric acid excretion [22], because generally hippuric acid is the glycine conjugate of benzoic acid. Because, hippuric acid synthesized in the liver and its production is greatly increased from benzoic acid based food substance or substances which generate benzoic acid during intermediate metabolism (e.g. polyphenols such as chlorogenic acid, quinic acid and caffeic acid) [20, 21]. Perhaps, based on the polyphenolic concentration, the hippuric acid elution was increased in the MEAE treated group urine sample, the hippuric acid excretion in the urine got increased with increase in MEAE dose in a dose depended manner. The commercial drug furosemide chemical name is (4-Chloro- $N$-furfuryl-5-sulfamoylanthranilic acid 5-(Aminosulfonyl)-4-chloro-2-([2 furanylmethyl] amino) benzoic acid) and the furosemide functional group benzoic acid conjugated with glycine may induce diuretics through hippuric acid formation, but that mechanism is still unclear.

On the other hand, secondary metabolites profile of MEAE by UPLC-MS/MS shows the presence of chlorogenic acid. Chlorogenic acid is well known plant secondary metabolite, which is responsible for inducing diuretic activity [23]. Similarly, plant secondary metabolites altered the diuretic markers like sodium, potassium and chloride levels in human urine $[24,25]$. From these results, the total volume of urine, sodium and potassium levels clearly indicate that the plant $M$. emarginata play crucial role for inducing diuretic activity. The presence of chlorogenic acid has been confirmed through RP-HPLC and UPLC-MS/MS and it might be responsible for inducing diuretics in animal model.

\section{Conclusion}

Based on the results we conclude that the M. emarginata can act as a good diuretic agent, without causing any side effects such as proteinuria or glycosuria. $M$. emarginata secondary metabolites may act as diuretic agents, especially chlorogenic acid and their byproducts. Chlorogenic acid byproduct, hippuric acid can act as a

Table 2 Effect of MEAE on hippuric acid concentration in urine samples collected from MEAE treated rats

\begin{tabular}{ll}
\hline Treatment Groups & Hippuric Acid (ng/ml) \\
\hline Control & $97.25 \pm 1.0^{\mathrm{e}}$ \\
Furosemide (20 mg/kg b.w.) & $566.3 \pm 5.87^{\mathrm{b}}$ \\
MEAE (200 mg/kg b.w.) & $240.8 \pm 4.04^{\mathrm{d}}$ \\
MEAE (400 mg/kg b.w.) & $494.9 \pm 3.51^{\mathrm{c}}$ \\
MEAE (600 mg/kg b.w.) & $620.7 \pm 8.38^{\mathrm{a}}$ \\
\hline
\end{tabular}

Mean \pm SD obtained from analysis of three independent samples, in duplicate abcde; in column, the superscript letters significantly differences in the mean at $(P<0.05)$ level 
diuretic agent as well as it could be used as a biomarker to detect the polyphenolics induced diuretic activity. However, the mechanism of chlorogenic acid inducing diuretics is unclear. Furthermore, additional studies need to be carried out to purify the bioactive compounds to evaluate diuretic activity and hippuric acid excretion analysis using animal as model system.

\section{Abbreviations}

CA inhibitors: Carbonic anhydrase inhibitors; CPCSEA: Control and supervision of experiments on animals; ESI: Electron Spray lonization; MEAE: M. emarginata aqueous extract; PDA: Photo Diode Array; RP-HPLC: Reverse Phase High Performance Liquid Chromatography; UPLC-MS: Ultra Performance Liquid Chromatography; USA: United States of America; $\lambda$ max: Maximum Absorbance

\section{Acknowledgements}

A.R thanks University Grants Commission (UGC), India for UGC Research Fellowship in Science for Meritorious students under Non-SAP programme and Bharathidasan University for providing University research scholar fellowship. Authors sincerely thank Department of Science and Technology (DST-FIST) and UGC-SAP, India for providing instrumental facilities to our department.

\section{Authors' contributions}

RA \& AAD have conducted all the experiments. ST has edited the manuscript. All authors read and approved the final manuscript.

\section{Ethics approval and consent to participate}

Experimental procedures and protocols were approved by the committee (BDU/IAEC/2012/33/28/03/2012) for the purpose of Control and supervision of experiments on animals, Chennai, Tamil Nadu, India.

\section{Consent for publication}

Not applicable.

\section{Competing interests}

The authors declare that they have no competing interests.

\section{Publisher's Note}

Springer Nature remains neutral with regard to jurisdictional claims in published maps and institutional affiliations.

\section{Author details}

${ }^{1}$ Department of Environmental Biotechnology, Bharathidasan University, Tiruchirappalli, Tamil Nadu 620024, India. ${ }^{2}$ Department of Food Quality and Safety, Gilat Research Center, Agricultural Research Organization, M.P. Negev - 85280, Tifrah, Israel.

Received: 3 July 2018 Accepted: 1 October 2018

Published online: 20 November 2018

\section{References}

1. Singh AK, Raghubanshi AS, Singh JS. Medical ethnobotany of the tribals of Sonaghati of Sonbhadra district, Uttar Pradesh, India. J Ethnopharmacol. 2002;81:31-41

2. Babu AV, Rao RSC, Kumar KG, Babu BH, Satyanarayanan PV. Biological activity of Merremia emarginata crude extracts in different solvents. Res J Med Plant. 2009;3:134-40.

3. Elumalai EK, Ramachandran M, Thirumalai T, Vinothkumar P. Antibacterial activity of various leaf extracts of Merremia emarginata. Asian Pac J Trop Biomed. 2011;1:406-8.

4. Flavio DF. Diuretics: drugs of choice for the initial management of patients with hypertension. Expert Rev Cardiovasc Ther. 2003;1:35-41.

5. Maland $\sqcup$, Lutz $\sqcup$, Castle $C H$. Effects of withdrawing diuretic therapy on blood pressure in mild hypertension. Hypertension. 1983:5:539-44.

6. Wright $\mathrm{Cl}$, Van-Buren L, Kroner $\mathrm{Cl}$, Koning MMG. Herbal medicines as diuretics: a review of the scientific evidence. J Ethnopharmacol. 2007; 114:1-31.
7. Jouad H, Lacaille-Dubois MA, Eddouks M. Chronic diuretic effect of the water extract of Spergularia purpurea in normal rats. J Ethnopharmacol. 2001;75:219-23.

8. Kreydiyyeh SI, Usta J. Diuretic effect and mechanism of action of parsley. J Ethnopharmacol. 2002;79:353-7.

9. El Bardai S, Lyoussi B, Wibo M, Morel N. Pharmacological evidence of hypotensive activity of Marrubium vulgare and Foeniculum vulgare in spontaneously hypertensive rat. Clin Exp Hypertens. 2001;23:329-43.

10. Odigie IP, Ettarh RR, Adigun SA. Chronic administration of aqueous extract of Hibiscus sabdariffa attenuates hypertension and reverses cardiac hypertrophy in 2K-1C hypertensive rats. J Ethnopharmacol. 2003;86:181-5.

11. Consolini AE, Baldini OA, Amat AG. Pharmacological basis for the empirical use of Eugenia uniflora L. (Myrtaceae) as antihypertensive. J Ethnopharmacol. 1999;66:33-9.

12. Navarro E, Alonso J, Rodriguez R, Trujillo J, Boada J. Diuretic action of an aqueous extract of Lepidium latifolium L. J Ethnopharmacol. 1994;41:65-9.

13. Kaur RG. Cow urine distillate as bioenhancer. J Ayurveda Integr Med. 2010;1:240-1.

14. Biswas S, Murugesan T, Maiti K, Ghosh L, Pal M, Saha BP. Study on the diuretic activity of Strychnos potatorum Linn. Seed extract in albino rats. Phytomedicine. 2001;8:469-71.

15. Souleymane M, Bahi C, Yéo D, Datte JY, Djaman JA, Nguessan DJ. Laxative activities of Mareya micrantha (Benth.) Mull. Arg. (Euphorbiaceae) leaf aqueous extract in rats. BMC Compliment Altern Med. 2010;10:2-6.

16. Bradford MM. A rapid and sensitive method for the quantitation of microgram quantities of protein utilizing the principle of protein-dye binding. Anal Biochem. 1976;7:248-54.

17. Dubowski KM. An o-toluidine method for body-fluid glucose determination. Clin Chem. 1962:8:215-35

18. Rameshkumar A, Sivasudha T, Jeyadevi R, Ananth DA, Pradeepha G. Effect of environmental factors [air and UV-C irradiation] on some fresh fruit juices. Eur Food Res Technol. 2012;234:1063-70.

19. Clifford MN, Knight S, Kuhnert N. Discriminating between the six isomers of dicaffeoylquinic acid by LC-MS(n). J Agric Food Chem. 2005;18:3821-32.

20. Păltinean R, Mocan A, Vlase L, Gheldiu A, Crisan G, lelciu I, et al. Evaluation of polyphenolic content, antioxidant and diuretic activities of six Fumaria species. Molecules. 2017;22:639.

21. Gonthier MP, Verny MA, Besson C, Remesy C, Scalbert A. Chlorogenic acid bioavailability largely depends on its metabolism by the gut microflora in rats. J Nutr. 2003;133:1853-9.

22. Rahim YA, Raizul ZM. Spectrophotometry semiquantitation method hippuric acid in urine for demonstration of toluene abuse. Indian J Forensic Med Toxicol. 2010;4:68-70.

23. Daly JW. Caffeine analogs: biomedical impact. Review Cell Mol Life Sci. 2007 64:2153-69.

24. Lawrence EA, Pumerantz AC, Roti MW, Judelson DA, Watson G, Dias JC, et al. Fluid, electrolyte, and renal indices of hydration during 11 days of controlled caffeine consumption. Int J Sport Nutr Exerc Metab. 2005;15:252-65.

25. Hailu $H$, Engidawork E. Evaluation of the diuretic activity of the aqueous and $80 \%$ methanol extracts of Ajuga remota Benth (Lamiaceae) leaves in mice. BMC Compliment Altern Med. 2014;14:135.

\section{Submit your manuscript to a SpringerOpen ${ }^{\circ}$ journal and benefit from:}

- Convenient online submission

- Rigorous peer review

- Open access: articles freely available online

High visibility within the field

- Retaining the copyright to your article

Submit your next manuscript at $>$ springeropen.com 